\title{
Technological Improvement and Public Politics in Acute Myocardial Infarction Treatment
}

\author{
Carvalho G* \\ Interventional Cardiology Federal University of Parana, Brazil \\ *Corresponding author: Carvalho G, Curitiba, Brazil
}

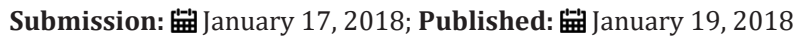

\section{Editorial}

In the face of a gigantic technological evolution in the study, diagnosis and treatment of cardiovascular diseases, they continue to be responsible for high rates of mortality and morbidity throughout the world. In this context, acute myocardial infarction is a major villain, abridging the active life of a growing population. Even with technological advancement in means for the adequate treatment of this pathology, these means become obsolete without measures to promote orientation of the population in recognizing their symptoms and seeking medical attention. At the same time, the public policies organized to promote the initial specialized treatment for patients should be instituted so that all the technological advances developed for the diagnosis and their respective treatment can be applied. Governmental measures have been promoted in several European countries (Stent for Life Program), in the United States of America, as well as in developing countries such as in Brazil, promoting an organized chain of care of acute myocardial infarction, from the recognition of the disease by the patients themselves to the specialized hospital treatment. This chain of service, along with the technological evolution we have has provided us with great successes in the conduct of this terrible disease that threatens a large part of the world population. 